\title{
DIFFRACTION IMAGING FOR BASEMENT FAULT-FRACTURE PREDICTION: APPLICATION TO AN OIL FIELD IN CUU LONG BASIN
}

\author{
Ta Quang Minh, Nguyen Danh Lam, Duong Hung Cuong, Pham Van Tuyen, Mai Thi Lua, Pham The Hoang Ha \\ Vietnam Petroleum Institute \\ Email: minhtq@vpi.pvn.vn \\ https://doi.org/10.47800/PVJ.2020.10-01
}

\section{Summary}

Improvement to the image of fractured granite basements is among the most sought-after goals for processing seismic data in Cuu Long basin, the most proliferous petroleum basin. Unlike a clear layering structure of the sediment, fuzzy images of the granite basement are often the source of confusion for interpreters to identify which structures are presented inside it. In such a low signal-tonoise ratio(SNR) environment, extracting geological information such as fault systems and fracture becomes challenging. In this study, diffraction imaging is employed in an effort to identify and enhance the fault system inside the basement. The comparison of the study result with various standard post-stack attribute approaches shows the effectiveness of the diffraction imaging method.

Key words: Seismic processing, seismic imaging, seismic diffraction, faults inside basement.

\section{Introduction}

In order to determine and identify fault systems from seismic data, traditional approaches usually use poststack processing to generate geometrical attributes that correlate to the characteristics of faults/fractures [1]. Most of the approaches include coherence-based methods [2], structure analysis [3] and curvature-based approaches [4]. The major assumption of these approaches is that the data contains images of "reflectors", and each method identifies either region of lacking reflections or the curvature/geometry of the reflections. These approaches work very well for sedimentary zones due to the layering nature of the sequence stratigraphy. However, when using the same approaches for the basement, the assumption is either weak or no longer valid. A better approach to study fault systems in the basement is to directly identify pre-migrated seismic events associated with the discontinuities in the medium, which, under seismic excitation, should generate diffraction waves. Thus, diffraction imaging techniques emerge as a possible direct approach to study the fault system in the basement.

Date of receipt: 19/8/2020. Date of review and editing: 19/8 - 18/9/2020. Date of approval: 18/9/2020.
The immediate challenge is the identification of diffraction signals (normally much weaker than reflection signals) in the usually low signal-to-noise ratio (SNR) environment of the basement, which directly impacts the possibility to perform diffraction imaging and identifies fault structure from the results.

In this study, the 3D seismic acquisition dataset for a small field in East Cuu Long basin (Figure 1), covering oil producing basement, was employed for the imaging/ special seismic attribute study. The seismic stack data quality (PSDM and CBM) was too fuzzy inside the basement to identify any fault system. Seismic data was reprocessed using the diffraction imaging workflow and the diffraction signatures were compared to the well data (including FMI). The very encouraging results from the study showed that diffraction imaging provided a much improved image of fault systems near and inside the basement, especially in comparison with those coming from various traditional post-stack attribute approaches.

\section{Theory and methodology}

The mechanism of post-stack seismic attributes for fault prediction involves either detecting the discontinuity of the reflection features (based on the geometrical analysis of continuous structural events) or identifying 
anticline features (based on the curvature of the events). These detections are to determine the fault/fracture signature indirectly (by the absence of continuity of reflection planes or the calculation of their geometrical curving properties) and the approach probably works well for sediment layers. On the contrary, the basement might not be the best place for poststack attribute fault detection because the continuity of reflections is not apparent.

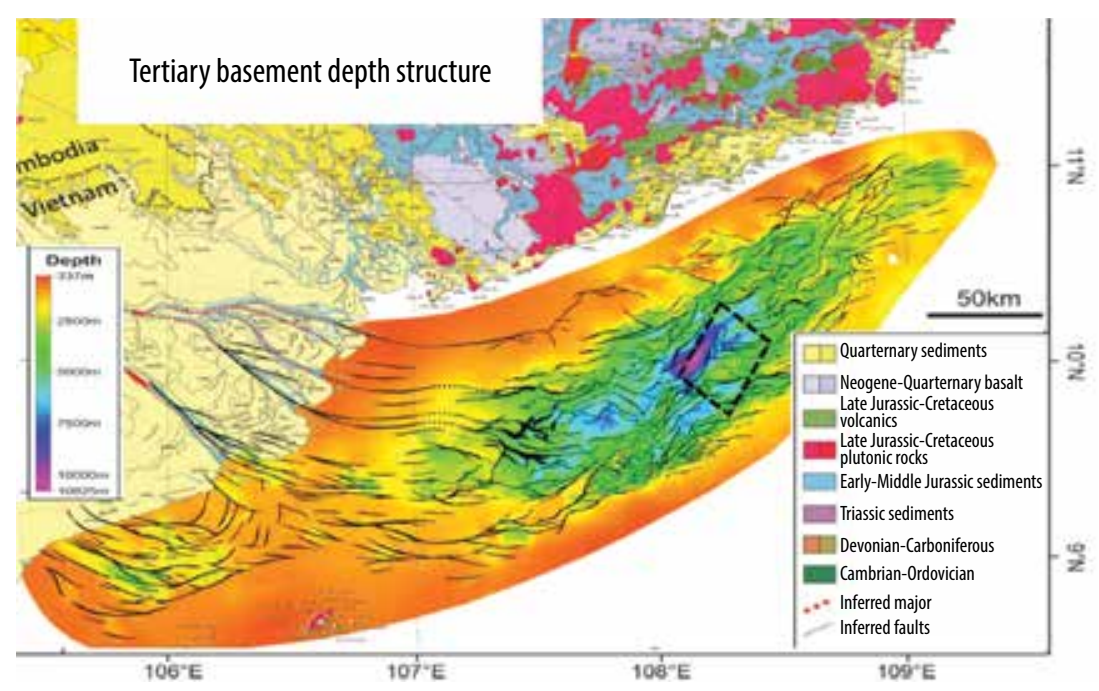

Figure 1. Tertiary basement map of Cuu Long basin and the study [5].
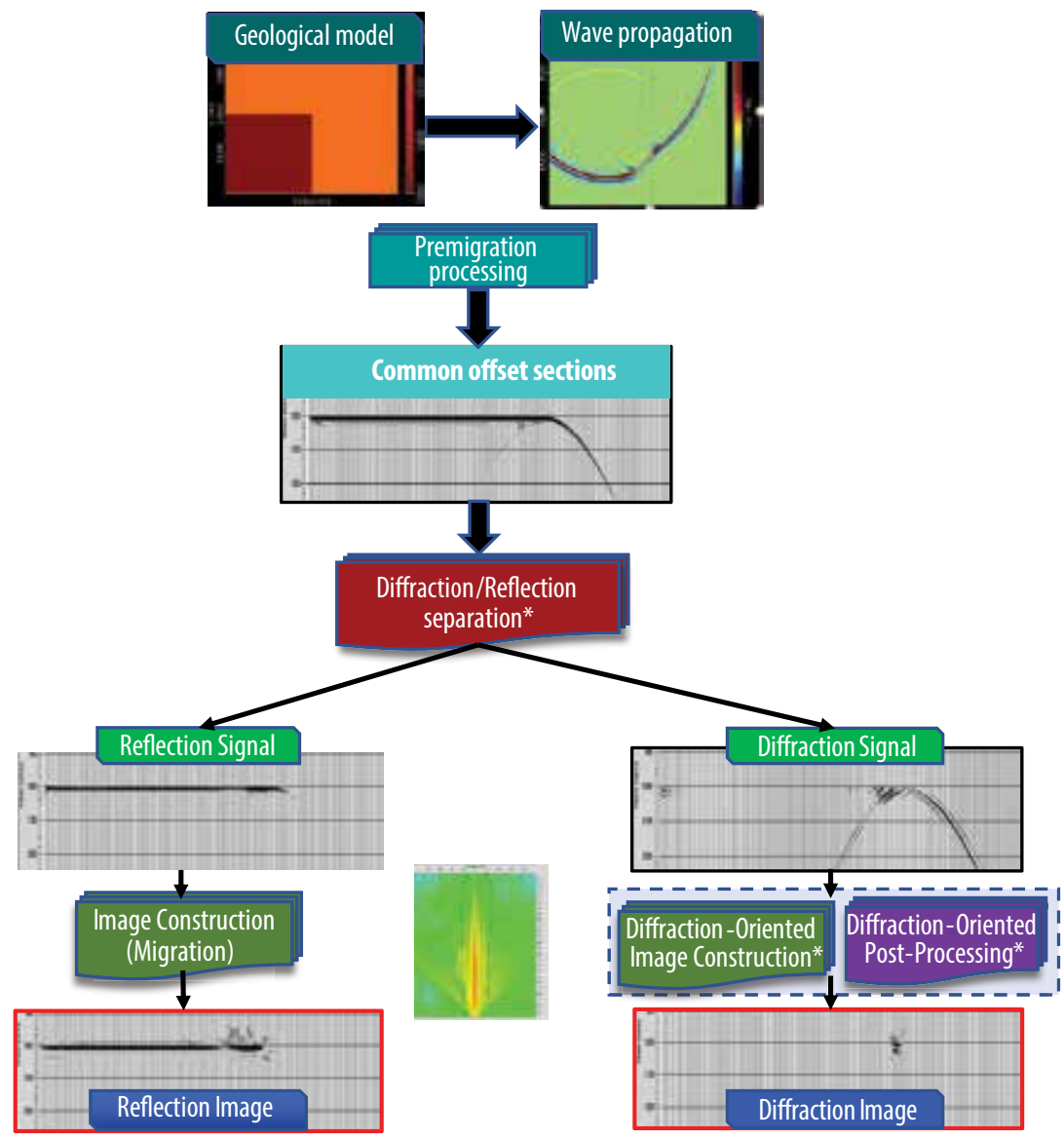

Figure 2. A simplified diffraction imaging workflow ( ${ }^{*}$ are VPI proprietary processing routines).
Stemming from the works of diffraction wave characterisation [6], a new form of seismic image called diffraction imaging [7], tries to separate diffraction wave from the reflection wave before the final seismic migration. The separation may come in the form of detecting continuous reflection event and remove it from the seismic using structure-oriented filtering such as plane-wave-destruction (PWD) [8], or multi-focusing [9]. Another way to accomplish the goal is to embed the reflection-diffraction separation as a part of the migration itself (such as side view seismic location - SVSL [10], velocity continuation method [11] or local angle domain [12]). A seismic cube of diffraction index is the result of such separation process. This cube of diffraction index can be further enhanced with post-stack fault prediction routines such as ant-tracking.

For this diffraction imaging study, we employed the plane-wave-destruction filtering approach of Fomel [8] for wavefield separation in combination with the velocity continuation imaging [11]. Summary of a diffraction imaging workflow (highly simplified) employed at VPI is shown in Figure 2. Here, the diffraction wave generated by a half plane model is properly separated and imaged just as described by Landa [7]. The improvement to the diffraction imaging of the actual field data is possible by pre-stack processing and other advanced migration techniques (proprietary right of VPI). However, even with the crude approach of velocity continuation imaging, we can observe the diffraction signature of fault systems with very high confidence.

Again, we note that: 1 . The lack of continuous reflection events in the basement makes the study of diffraction highly important. 2. Unlike post-stack attributes, diffraction imaging attribute 
cubes are the direct indicator of discontinuous events (faults, fractures). 3. The amplitude of diffraction signal is several orders of magnitude less than the reflection, making the method applicability questionable for the basement, hence the real data of an oil field needs to be checked for effectiveness.

\section{Application to a basement field data in Cuu Long ba- sin, offshore Vietnam}

\subsection{Studied area and the database}

The target of the diffraction study is the granite fractured reservoir of an oil field situated to the east of Cuu Long basin (Figure 1). Map of the top Tertiary basement in this area indicates some horsts divided by E-W faults. These horsts show the separation with adjacent grabens by NE-SW faults, many of them are thrust faults which are considered as the results of inversion activity in Oligocene. The conventional seismic allows to confidently define only some fault systems with large displacement observed at the top of the basement. There are several wells penetrating inside the basement confirming the very good oil flow in this reservoir. However, dry wells in the same anticline structure imply the oil and gas might be accumulated in different special spaces that are mainly controlled by the faults/fractures inside the Tertiary basement since the granular porosity is considered negligible.
The seismic data employed by the study include poststack data (PSDM) to generate the traditional attributes, as well as the pre-migrated seismic (slightly preconditioned) to be input for the diffraction image processing. Results of the processing and comparison between the two approaches are presented next.

\subsection{Initial diffraction imaging results in the sediment near top basement}

As a test case, a sedimentary section is examined (Figure 3), where large faults can readily be seen and interpreted from the seismic sections. Diffraction imaging indicators show a good match between those of high amplitudes and the seismic-stack-based interpreted faults. A time-slice through a region with faults also emphasises the fact that the diffraction imaging indicator can highlight individual faults whereas those from the stack are not so clear.

\subsubsection{Intra-basement analysis at a well location}

FMI data from three wells indicated fault systems with very high dip angle $\left(56-88^{\circ}\right)$. Most of the FMl indicates the occurrence of complex conjugate faults. Among them, a vertical well (Well \#1) is employed to illustrate the study.

Figure 4 indicates seismic profile (PSDM) going through exploration Well \#1 superimposed with the faults from FMI. By FMI and well information (from the FMI and
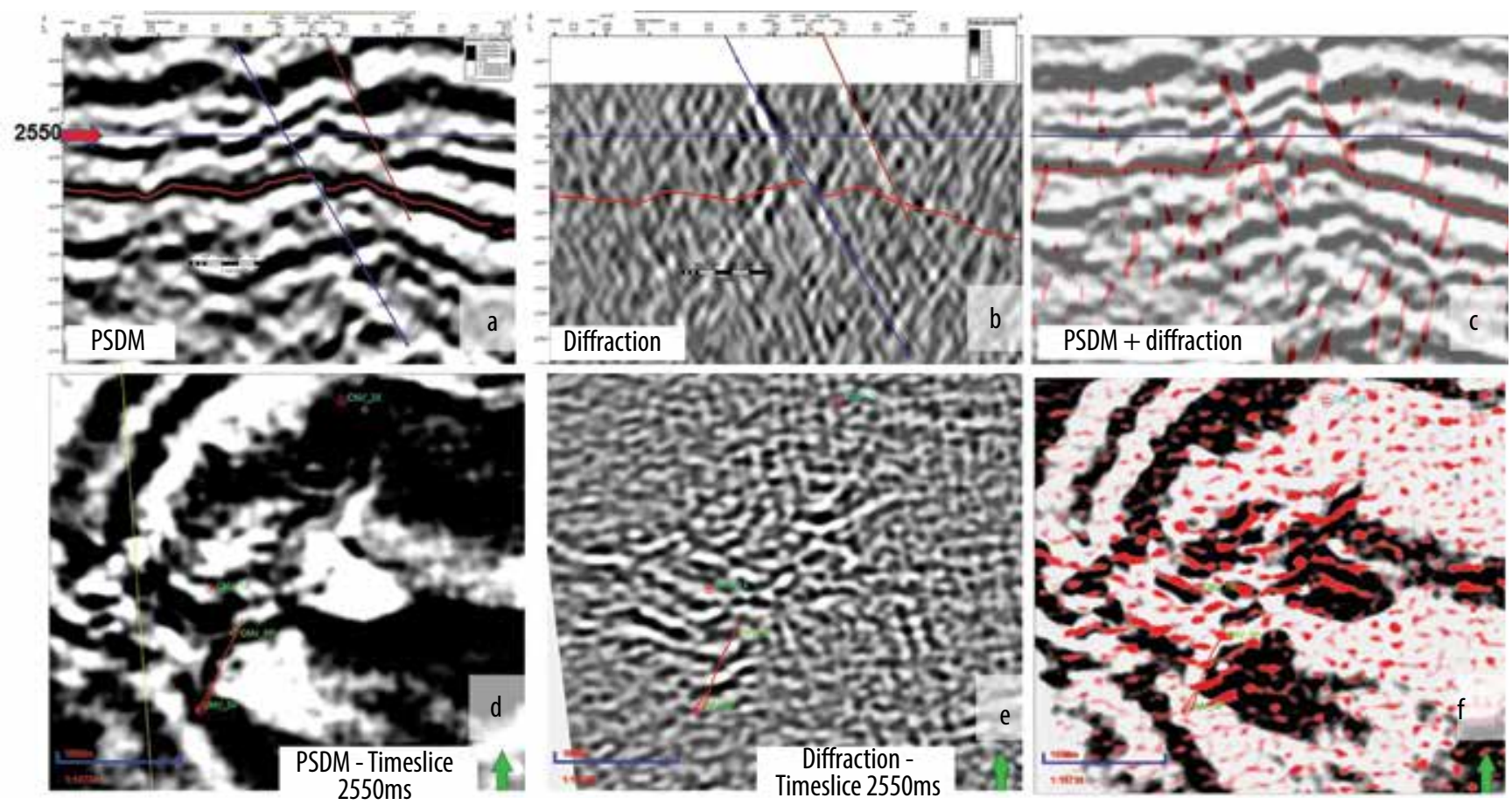

Figure 3. Diffraction imaging in the sediment section. (a) PSDM stack (b) Diffraction index (c) Diffraction index coincides with the identified faults on the overlaid PSDM section. Time slice of (d) PSDM cube over a region with faults (e, $f$ ) Diffraction image with fault interpretation. 
well reports), at least three zones have been identified related to faults and fractures. There are three fault zones interpreted from different depth levels including Zone \#1 ( 3,725 - 3,860 mTVDSS), Zone \#2 ( 4,320 mTVDSS) and Zone \#3 ( 4,480 mTVDSS). The first zone contains two main fault systems, ENE-WSW striking sets conjugate with striking

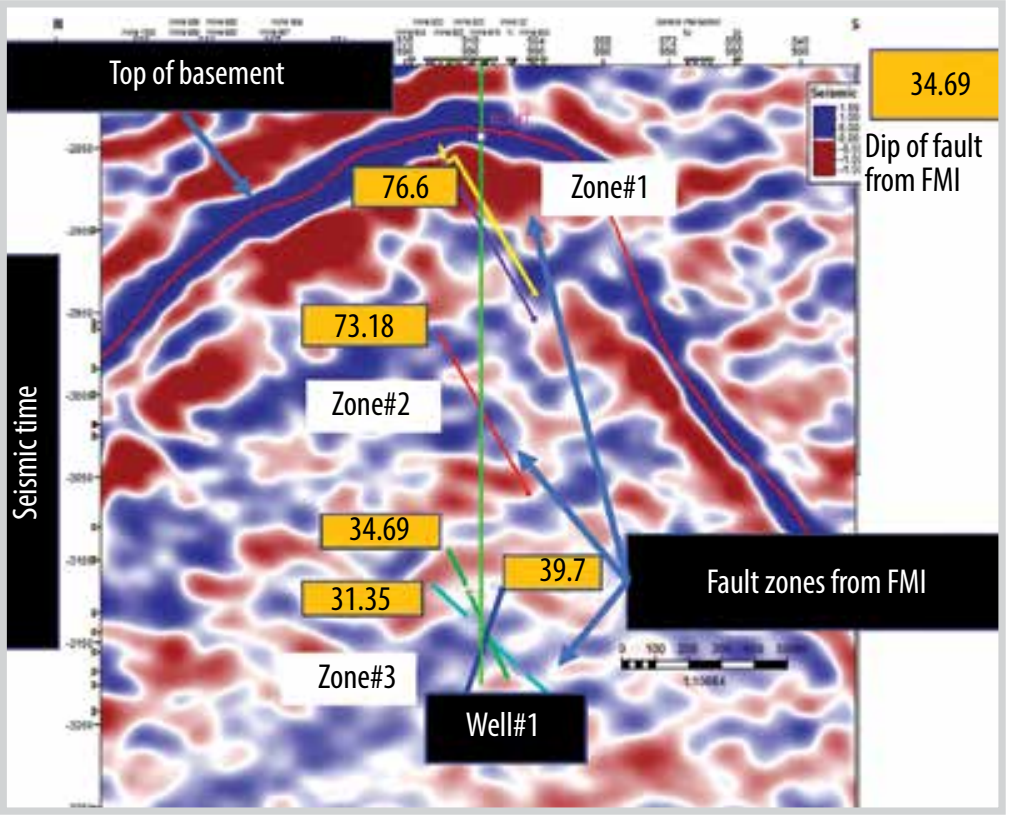

$\mathrm{N}-\mathrm{S}$ sets. The second zone is characterised by a NW-SE strike with the dip of $73^{\circ}$. Two conjugate faults are imaged by FMI data with strike of NE-SW and NW-SE in the Zone \#3, the dips of these faults range from $31^{\circ}$ to $39^{\circ}$. In Figure 4, the faults identified by FMI in each zone are displayed by different colours.

Examining the conventional PSDM section, hints of the faults inside the basement can be barely spotted (Figure 4), however, the interpretation could be quite ambiguous. In other words, most of the fault zones are not quite observable from the standard (reflection) seismic section.

\subsubsection{Traditional approaches - standard post- stack attributes to identify faults}

Previous post-stack attribute study has been carried out to identify the fault system (Figure 5) where geometrical extraction properties (such as chaos and variance) are used before using the "ant-tracking" routine

Figure 4. FMI data indicates the characters of fault system inside the basement.
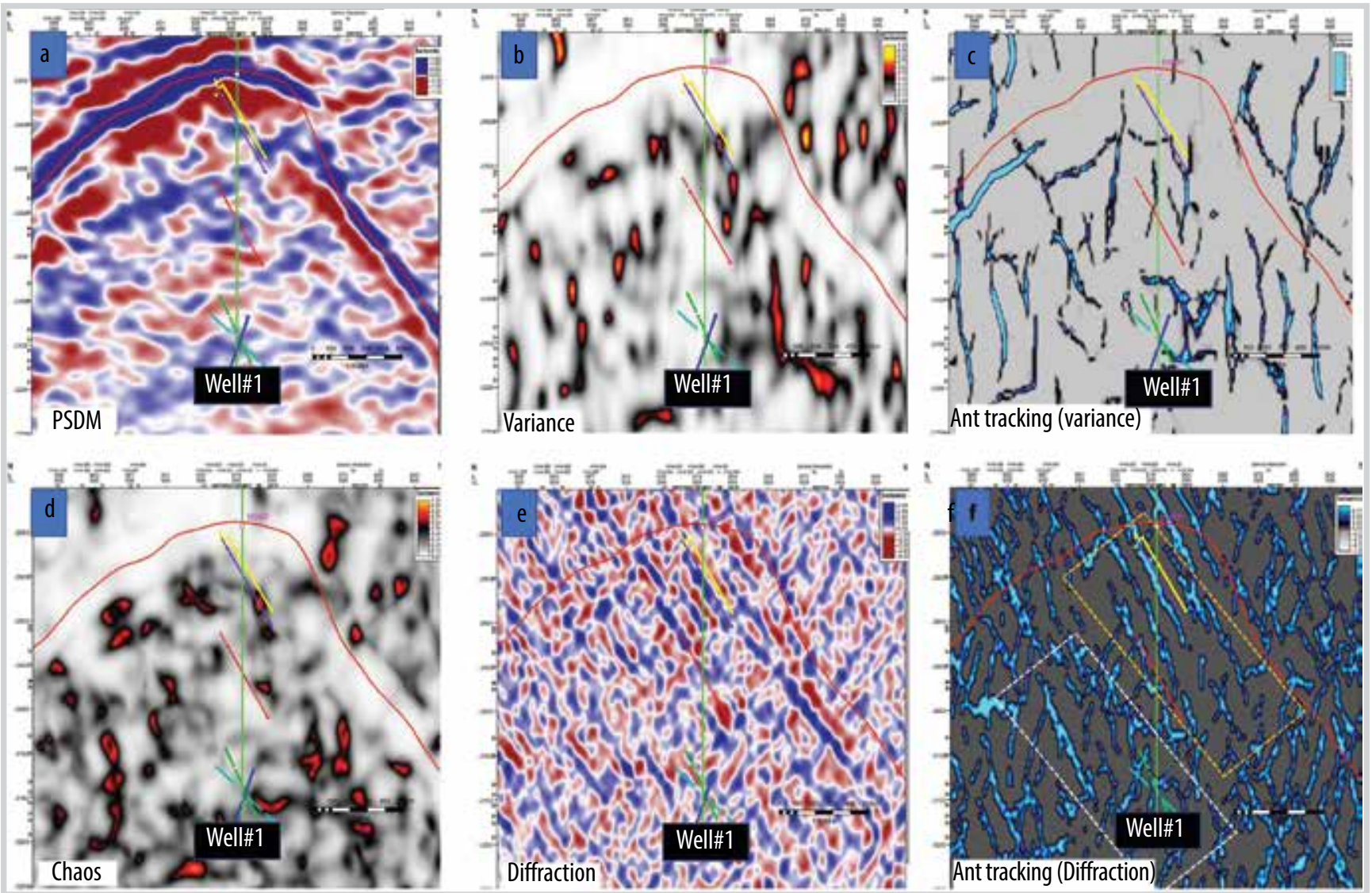

Figure 5. (a) Seismic profile (same with Figure 4) and several popular seismic attributes including (b) variance (c) ant-tracking (d) chaos and (e) diffraction and $(f)$ ant-tracking of diffration data. 


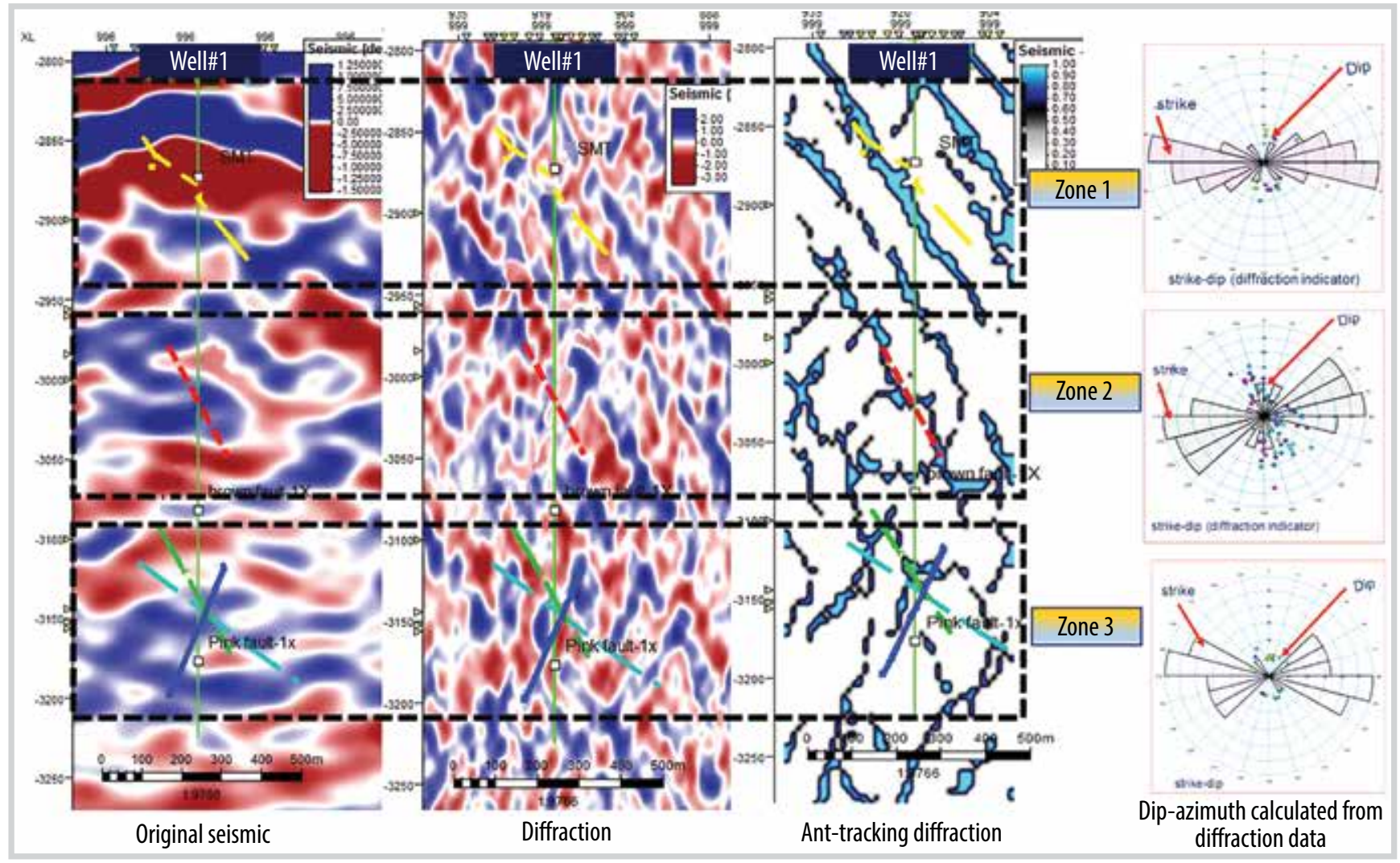

Figure 6. Seismic profile going through vertical Well\#1. The faults based on FMI in three zones are demonstrated by colour sticks. Rose diagrams indicate the strike and dip faults based on the diffraction data.

to extract the fault system. Most of the attributes show the evidence of uppermost faults (yellow and purple lines), however these attributes indicate neither clearly (chaos, variance) nor fully this fault (ant-tracking). A mismatch between the dip, azimuth of the other estimated faults and the actual values from the FMl logs indicates an unsuccessful attempt. Also, many vertical events appear with the dip of nearly $90^{\circ}$ which is not suitable with the observation from the FMIs.

The reflector associated with the top basement disappeares in the diffraction section, this dataset describes several oriented events. There are two portions around well's location, the first part (yellow rectangular) witnesses the dominance of anomalies which shares the same trend with fault Zones \#1 and \#2. The conjugates of fault Zone \#3 are mapped in the second part (white rectangular).

\subsubsection{Fault identification using the diffraction index}

Figure 6 compares the section of an exploration well versus PSDM seismic, diffraction data and the ant-tracking based on the diffraction data.

In the PSDM section, the top of the basement is tied to a strong reflector, all FMI-based faults are overpowered by the large reflection seismic phase, hence the faults become invisible. On the contrary, the strong reflector related to the top of the basement is removed in diffraction data and the conjugate alignments are shown. In the first zone, the diffraction and ant-tracking from this data showed quite well the two alignment systems with E-W orientation, the NW-SE system was quite faint. In the second zone, the diffraction mainly depicts faults of E-W direction and a small part of $\mathrm{N}-\mathrm{S}$ direction, the instruction at FMI was mainly for NW-SE direction. Third zone's diffraction index clearly shows two NW-SE \& conjugate systems which is similar to FMI.

\subsection{Comparisons of post-stack attributes and the diffraction index on regions beyond wells}

Figure 7 shows sections with two proven faults (yellow dash lines) confirmed by the movement of seismic phase observed (on the seismic section) at the top of the basement and nearby wells. Standard attributes (variance, chaos, and positive curvature) are computed but they all show an ambiguous image of faults inside the basement, implying poor SNR in conventional seismic images.

Events on the variance and chaos attribute section look like some localised spots without any systematic 


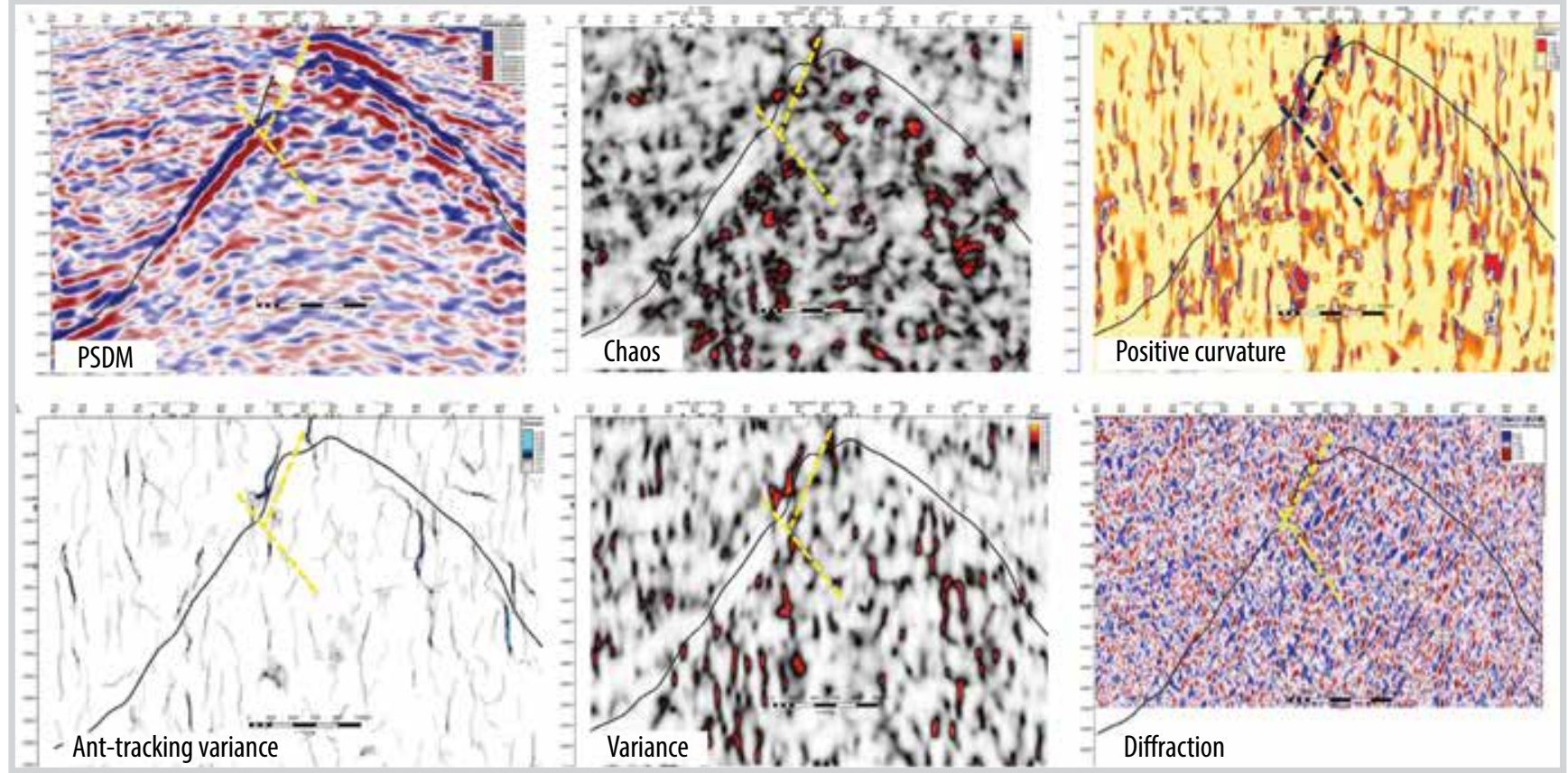

Figure 7. Comparison among standard seismic attributes, two dash lines indicate some proven faults.
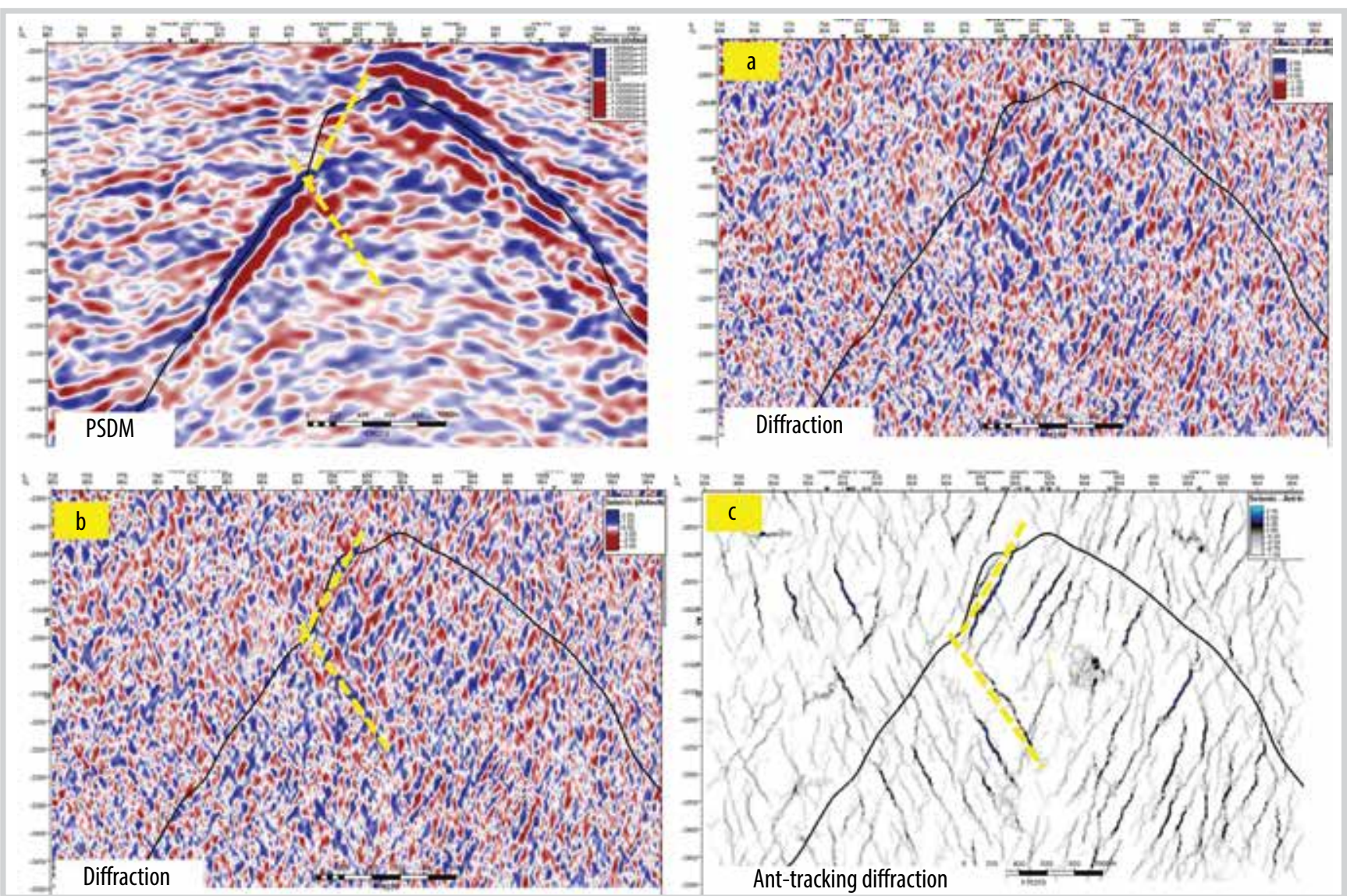

Figure 8. (a) Diffraction section (b) with interpreted fault and (c) ant-tracking of diffraction index.

coherence to indicate fault features. The positive curvature section provides better lineament highlighted events related to the fault on the left but not the one on the right. Vertical events with the dip of nearly $90^{\circ}$ are still present and difficult to explain from the geological perspective.
Figure 8 shows the diffraction section, where the presence of at least two conjugated fault systems are observed. The indices have good coherency that can link together to form a fault. The fault on the right is clearly shown on the diffraction section. More illustration of the 


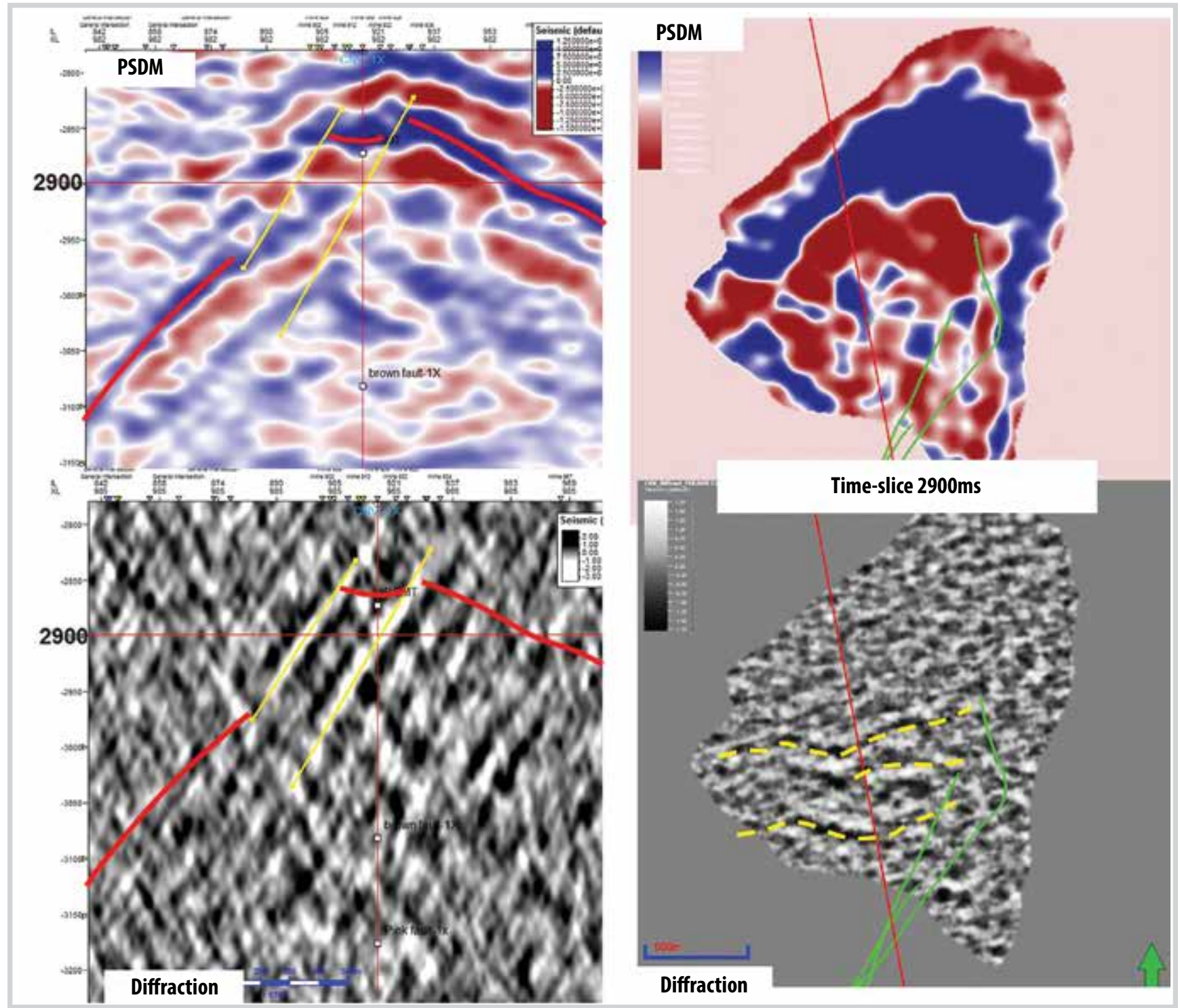

Figure 9. A time slice through the basement segment to compare the PSDM and diffraction image.

effectiveness of the diffraction approach vs common migrated section (lack of fault signature) is demonstrated in Figure 9, where a time-slice extracted from diffraction shows clear evidence of coherence faults, which is invisible on PSDM slice.

Figure 10 shows the sections from some more advanced post-stack seismic attributes including similarity, instantaneous dip, Kingdom's similarity variance and dip variance, which appear to show better fault features. However, some of the faults that can be readily seen/ identified from the seismic stacks and the diffraction section are still missing from the attributes. Moreover, since these advanced post-stack seismic attributes are still indirect indicators of faults, their amplitude do not carry the same interpretable property as the amplitude of the diffraction index, which may connect to the petroleum potentials.

\section{Conclusions}

Diffraction imaging is a new approach of extracting wave-related information from seismic data (excluding reflection signals), which iscrucial in imaging discontinuous geological events including faults and fractures. Given the low SNR of the seismic signal inside the basement, a crude calculation diffraction imaging effort was carried out. The results highlight the fact that it is possible to improve the image of the fault system inside the basement using diffraction imaging, which is confirmed by the well data and seismic phase displacement. Further post-stack enhancement to the diffraction imaging technique will certainly improve images for reliable prediction of the fault/fracture system within the granite basement. 


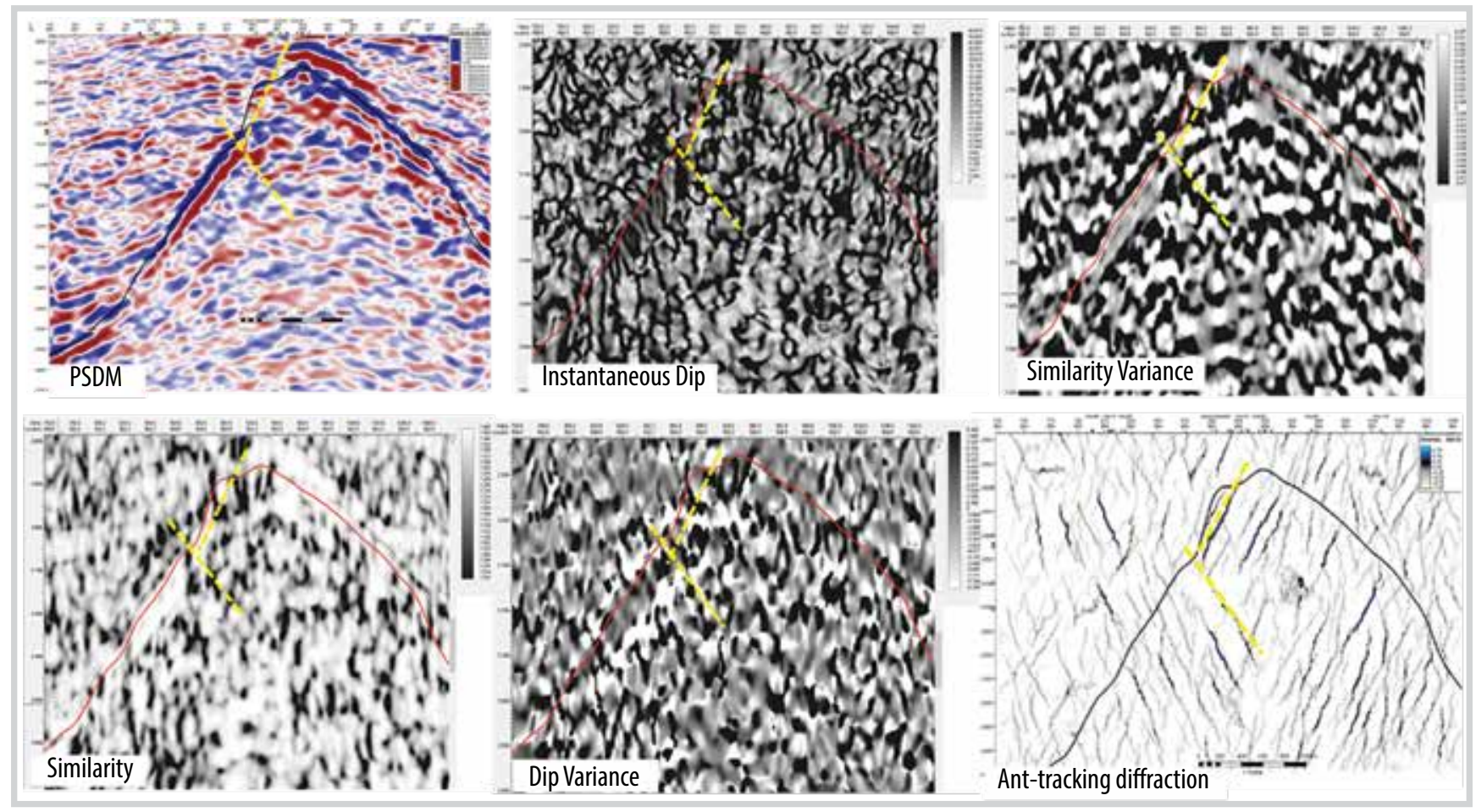

Figure 10. Comparison of some advanced post-stack seismic attributes. Two yellow dash lines are some proven faults.

\section{References}

[1] Satinder Chopra and Kurt J. Marfurt, Seismic attributes for prospect identification and reservoir characterization. Society of Exploration Geophysicists, 2007. DOI: 10.1190/1.9781560801900.

[2] Mike S. Bahorich, John Lopez, Norman Lopez, E. Nissen, and Alan Poole, "Stratigraphic and structural interpretation with 3-D coherence", SEG Technical Program Expanded Abstracts 1995. DOI: 10.1190/1.1887435.

[3] Gijs C. Fehmers and Christian F.W. Hocker, "Fast structural interpretation with structure-oriented filtering", Geophysics, Vol. 68, No. 4, 2003. DOI: 10.1190/1.1598121.

[4] Richard J. Lisle, "Detection of zones of abnormal strains in structures using Gaussian curvature analysis", AAPG Bulletin, Vol. 78, No. 12, pp. 1811 - 1819, 1994.

[5] William Schmidt, Bui Huy Hoang, James W. Handschy, Vu Trong Hai, Trinh Xuan Cuong, and Nguyen Thanh Tung, "Tectonic evolution and regional setting of Cuu Long basin, Vietnam", Tectonophysics, Vol. 757, pp. 36 - 57, 2019. DOI: 10.1016/j.tecto.2019.03.001.

[6] K.D. Klem Musatov and A.M. Aizenberg, "The ray method and the theory of edge waves", Geophysical Journal of the Royal Astronomical Society (Geophysical Journal International), Vol. 79, No. 1, pp. 35 - 50, 1984. DOI: 10.1111/j.1365-246X.1984.tb02839.x.
[7] E. Landa, V. Shtivelman, and B. Gelchinsky, "A method for detection of diffracted waves on commonoffset sections", Geophysical Prospecting, Vol. 35, No. 4, pp. 359 - 373, 1987. DOI: 10.1111/j.1365-2478.1987.tb00823.x.

[8] Sergey Fomel, "Applications of plane-wave destruction filters", Geophysics, Vol. 67, No. 10, pp. 1946 1960, 2002. DOI: 10.1190/1.1527095.

[9] Boris Gelchinsky, Alexander Berkovich, and Shmariahu Keydar, "Multifocusing homeomorphic imaging. Part 1: Basic concepts and formulas", Journal of Applied Geophysics, Vol. 42, pp. 229 - 242, 1999.

[10] O.L. Kouznetsov, I.A. Chirkin, I.S. Faizulline, B.Y. Meltchouk, I.S. Dzhafarov, Y.A. Kuryanov, V.N. Nesterov, S.I. Slenkin, G.V. Kashirin, Z.H. Mollaev, and A.P. Kozub, "Improving the efficiency of seismic exploration by applying 3D mapping of open fracturing by the SVSL method", Conference Proceedings, 64 ${ }^{\text {th }}$ EAGE Conference \& Exhibition, Florence, Italy, 27 - 30 May, 2002. DOI: 10.3997/2214-4609-pdb.5.G038.

[11] Luke Decker, Dmitrii Merzlikin, and Sergey Fomel, "Diffraction imaging and time-migration velocity analysis using oriented velocity continuation", Geophysics, Vol. 82, No. 2, 2017. DOI: 10.1190/geo2016-0141.1.

[12] Igor Ravve, Zvi Koren, Allon Bartana, and Dan Kosloff, "Local angle domain in seismic imaging", $69^{\text {th }} E A G E$ Conference and Exhibition incorporating SPE EUROPEC, 11 14 June, 2007. DOI: 10.3997/2214-4609.201401932. 